\section{Repair of non-obstetrical vesicovaginal fistula: a 13-year experience of single Irish institution}

\author{
Jawad ul Islam, Ronald Grainger, \\ Ted McDermott, Robert Flynn, \\ John Thornhill
}

Adelaide \& Meath Hospital, Tallaght, Dublin, Ireland

\section{Abstract}

The objective of this study was to review our clinical experience in the surgical management of non obstetrical vesicovaginal fistulae (VVF) over the past 13 years, to determine common causes of fistulae in a modern hospital setting and outcomes based on different surgical approaches and timing of repair. A retrospective review of patients with VVF at the Adelaide Meath Hospital, Dublin, was undertaken from January 1997 to June 2010. 35 patients with mean age of 32 years (range 17 to 53 years) with vesicovaginal fistulae underwent surgical repair. A percentage of 68.5 fistulae occurred post hysterectomy, $20 \%$ were due to pelvic malignancy and the remainder from other causes. With regards to the timings of surgery, $57 \%$ were repaired within 3 months, $11 \%$ within 6 months and $32 \%$ after 6 months. $57 \%$ of patients underwent abdominal repair of fistulae and $26 \%$ had vaginal repair. 6 patients were not suitable for any type of repair and hence had urinary diversion. There were 3 failures, all after abdominal repair for complex fistulae. Timing of surgery has no apparent impact on the final outcome of the fistula. The type of approach depends on the preference and experience of the surgeon, with different approaches offering equally good results at our institution. Urinary diversion is still an option for a select group of patients.

\section{Introduction}

In developing countries, the majority of the vesicovaginal fistulae (VVF) are due to prolonged childbirth, ${ }^{1}$ causing tissue pressure necrosis between the vagina and bladder. Etim et al. in his recently published study, conducted in Nigeria, showed that 49 genito-urinary fistulae were diagnosed out of 4520 deliveries, with an incidence of 8.2 per 1000 . In developed countries, $75 \%$ follow hysterectomy, other causes include pelvic surgery, radiotherapy, advanced malignancy, pelvic endometriosis, inflammatory bowel disease and trauma. ${ }^{2}$

This unpleasant complication leaves affected women with continuous urinary incontinence leading to excoriation of the vulva and vagina. The social consequences are severe due to continuous wetness and smell of urine which isolates many affected women from the community. According to a recent study conducted in Cameroon, $15 \%$ of patients with vesicovaginal fistulae suggested that suicide seemed to be the solution to their fistula problem. ${ }^{3}$ The key to successful repair of VVF lies in the classic principles defined by Couvelaire in 1953 , good visualization, good dissection, good approximation of the margins and good urine drainage. ${ }^{4}$ These principles can be achieved, either by vaginal or abdominal approaches.

Although the choice of technique partly depends on the characteristics of the fistula (site, size, clinical context), it also depends on the experience of the surgical team. Most uncomplicated VVFs, both trigonal and supratrigonal, can be managed through the transvaginal route, particularly by using maneuvers to bring the fistula closer to the operating surgeon. ${ }^{5,6}$ More complex fistulae may require the transabdominal route for optimal repair. ${ }^{7,8}$

The objective of this study was to review retrospectively our clinical experience in the surgical management of vesicovaginal fistulae over the past 13 years, to determine common causes of fistulae in a modern hospital setting and outcome based on different surgical approaches and timing of repair.

\section{Materials and Methods}

A retrospective review at Adelaide Meath Hospital, Dublin, undertaken from January 1997 to June 2010, recorded 35 patients with vesicovaginal fistulae due to non obstetrical causes, who underwent surgical repair. The mean age of these patients was 32 years (range 17 to 53 years). These included all patients presenting to us during this period and were referred by primary and secondary healthcare centers. Data was recorded on etiology, site, size and numbers of fistulae, the surgical approach and complications. The time from the occurrence of fistula to referral was noted to determine if that had any impact on the final outcome of fistula repair.

Most patients referred to us were already diagnosed with VVF but all patients were evaluated preoperatively by history, physical examination, serum creatinine and intravenous urography. Sixteen patients underwent cystogram and 3 had methylene blue test. Cystoscopy was performed in all patients to determine the site, size and numbers of fistulae along with an assessment of the urothelium adjacent to the fistulous opening. Vaginal
Correspondence: Jawad ul Islam, Urology Department, Adelaide \& Meath Hospital, Tallaght, Dublin 24, Ireland.

Tel. +35.314144120 - +35.314144124.

E-mails: drjawad@yahoo.com - marjorie.whiteflynn@amnch.ie

Key words: non-obstetrical, vesicovaginal, fistula.

Contributions: JUI, project development, data collection, manuscript writing; JT, project development, data analysis, manuscript editing; RG, manuscript editing, data analysis; $\mathrm{TMcD}, \mathrm{RF}$, manuscript editing.

Conflict of interests: the authors declare no potential conflict of interests.

Received for publication: 19 January 2013.

Revision received: Not required.

Accepted for publication: 23 April 2013.

This work is licensed under a Creative Commons Attribution NonCommercial 3.0 License (CC BYNC 3.0).

(C) Copyright J. ul Islam et al., 2013

Licensee PAGEPress, Italy

Urogynaecologia 2013; 27:e1

doi:10.4081/uij.2013.e1

speculum examination assessed vaginal capacity and vaginal skin integrity. On the basis of site, size, etiology and associated anomaly, fistulae were divided in two groups, simple and complex. Fistulae associated with ureteric involvement, previous failed fistula surgery or large size, were regarded as complex fistulae. All simple fistulae were repaired through vaginal route and complex fistulae through abdominal route. Extensive fistulae not amenable to repair underwent urinary diversion with ileal conduit. Patients were followed up at six weeks, three months, nine months and later on depending on the presence of symptoms.

\section{Results}

The etiology of fistulae in 35 patients in our study was as follows (Table 1). Twenty four patients (68.5\%) developed VVF after hysterectomy. Among these, 21 patients had abdominal and 3 vaginal hysterectomy. Most of these hysterectomies were for benign disease except 7 cases where the cause was malignancy ( 4 cervical, 2 endometrial and 1 ovarian cancer). Three of the cervical cancer patients also had adjuvant radiotherapy. Seven patients (20\%) had pelvic malignancy as the cause of VVF, of whom, 3 were due to bladder cancer, 3 from cervical cancer and one from rectal cancer. All 
3 cervical cancer patients had prior radiotherapy. Two of these patients developed recurrent disease along with VVF and hence were managed with radical surgery and ileal conduit. Two bladder cancer patients presented with locally advance disease leading to VVF which underwent radical cystectomy and ileal conduit. Third patient with bladder cancer developed VVF 6 months post radiotherapy and hence was also managed with radical cystectomy and ileal conduit. Rectal cancer patient had pelvic exenteration and ileal conduit. Hence six patients $(17 \%)$ were not suitable for VVF repair and underwent urinary diversion (Table 2). One patient (3\%) developed VVF after anterior repair of cystocele. Among the remaining three VVF cases (8.5\%), 2 occurred after nongynaecological pelvic surgery and one after foreign body insertion by the patient.

Twenty patients (57\%) with VVF were considered as complex fistulae and hence were repaired by trans-abdominal approach. Three of these had associated ureteric involvement and needed simultaneous ureteric reimplantation. Two had history of previous failed VVF repair and rest had large or multiple fistulae. Nine patients (26\%) underwent vaginal repair. We evaluated the time period from the occurrence of fistula and referral. Twenty patients (57\%) were referred within 3 months after diagnosis. Another 4 patients (11\%) came to us within 6 months but 11 patients (32\%) had symptomatic fistula for more than 6 months before referral.

\section{Vaginal repair technique}

When the vaginal route was used both ureters were catheterized cystoscopically to safeguard them during repair. After identification of the fistula, a small-sized Foley catheter was introduced through the vaginal opening of the fistula into the bladder. Traction on the catheter helped to bring the fistula closer to the operating surgeon. When the fistula lumen was too small for catheter placement, a guide wire was passed and the fistulous track was dilated to facilitate passage of a small Foley catheter over the guide wire. A vaginal mucosal $U$ shaped incision was made after saline infiltration into the mucosa. A generous plane between the bladder and vagina was developed at least 2 $\mathrm{cm}$ beyond the fistulous opening to develop adequate vaginal flaps for layer closure. The fistula was closed without excising it and its walls were included in the first layer of closure which provided a strong anchor of supporting tissue. Fistula repair was performed in three layers. The first layer was created by approximating the fistula edges at the bladder wall. Second layer was created by approximation of perivesical fascia over the first layer. Third layer of repair involved the closure of vaginal flaps. The bladder was drained with urethral catheter only, in all patients for 10 to14 days postoperatively.

\section{Abdominal repair technique}

Fistula repair through the abdominal route was carried out using the 0 'Conor technique. ${ }^{9}$ At preliminary cystoscopy both ureters were catheterized before opening the abdomen. The bladder was bivalved to the fistula site and then dissected off the vagina. Bladder and vagina were closed separately and an interposition graft was placed in all cases using omentum or pelvic peritoneum. Suprapubic and urethral catheters were placed to ensure bladder drainage postoperatively. The catheters were removed from 7 to 21 days post operatively depending on the surgeon's preference. All patients were maintained on oral anticholinergics to avoid bladder spasms. Full-dose prophylactic antibiotics were administered in the perioperative period for three days followed by ciprofloxacin daily until the catheter was removed. Patients were evaluated at six weeks, three months, nine months and later on depending on the presence of symptoms. Abstinence from sexual intercourse was advised for three months postoperatively.

Table1. Etiology of vesicovaginal fistula.

$\begin{array}{lcc}\text { Causes } & \text { Numbers of patients } & \% \text { age } \\ \text { Post hysterectomy } & 21 & 68.5 \\ \quad \text { Abdominal } & 3 & \\ \quad \text { Vaginal } & 24 & \\ \quad \text { Total } & & \\ \text { Pelvic malignancy } & 3 & 20 \\ \quad \text { Bladder } & 3 & \\ \text { Cervical } & 1 & 3 \\ \text { Rectal } & 7 & 8.5 \\ \text { Total } & & \\ \text { Gynecology surgery } & 1 & \\ \quad \text { Anterior repair of cystocele } & & \\ \text { Other causes } & 2 & \\ \quad \text { Non-gynecological pelvic surgery } & 1 & \\ \text { Vaginal foreign body } & 3 & \\ \text { Total } & \end{array}$

Table 2. Type of surgery performed.

\begin{tabular}{lcc} 
Type of surgery & Numbers of patients & $\%$ age \\
Abdominal repair & 20 & 57 \\
Vaginal repair & 9 & 26 \\
\hline Urinary diversion & 6 & 7 \\
\hline
\end{tabular}

Table 3. Outcome of repair.

\begin{tabular}{lcc} 
Type of surgery & Successfu & Failures \\
Abdominal & 20 & 3 \\
Vaginal & 9 & 0 \\
\hline Ileal conduit & 6 & 0
\end{tabular}

Three cases (9\%) had recurrence of fistula after surgery (Table 3 ). The interval between occurrence of fistula and repair surgery had no patients operated within 3 months failed. Four patients had their surgery within 3 to 6 months and 1 failed. Similarly 1 failure was found in 11 patients who had repair after 6 months.

\section{Discussion}

As in other developed nations, VVF is rare in Ireland. But when it occurs, it has serious impact on the quality of life, is socially debilitating and has important medico legal implications. In our study the most common circumstance in which VVF occurred was post hysterectomy (68.5\%), as has been reported in other large series. Goodwin reported $75 \%$ of his cases were of gynecological origin, ${ }^{10}$ and Lee reported $82 \%$ resulted from gynecological surgery, and only $8 \%$ from obstetric complicaimpact on outcome of the repair. One of 20 
tions. ${ }^{11}$ Although management is more standardized in recent decades, the surgical approach remains an issue of contention for the repair of VVF. The fundamental treatment principles for VVF can be achieved through both, vaginal and abdominal route, depending upon surgical experience.

In our study there were three failures with an overall success rate of $91 \%$. All of these were after abdominal repairs and none after vaginal repair. 2 of these cases had abdominal with adjuvant radiotherapy for cervical cancer. Third case had multiple fistulae along with ureteric fistula after a complicated hysterectomy for benign disease. The success rate in most series varies between $75-95 \%$ with various techniques. ${ }^{12,13}$ The advantages of transvaginal repair are less invasiveness, less blood loss, decreased post operative pain, early mobilization and less hospital stay. ${ }^{14}$ The disadvantage of this approach is the limited access. The advantages of the abdominal approach are good exposure of the fistula hence it is better suited for complex fistulas. Factors such as size of fistula, proximity of fistula to the ureteric orifice and time interval since injury do not affect the choice of repair and nowadays there is a trend more towards the transvaginal approach. ${ }^{15}$ Timing of repair used to be an issue in the past and most surgeons waited for six months. Most recent studies favor early repair. Langkilde et al. in his study of 13 patients operated within three months of the iatrogenic lesion, reported no recurrence or increased morbidity. ${ }^{2}$ In our uncontrolled study, there was no apparent impact on the outcome by early versus late repair of fistula. All 3 failures belonged to different groups i.e. 1 patient was referred within 3 months of occurrence, 1 between 3 to 6 months and 1 patient was delayed for more than 6 months before referral. The 6 cases not suitable for fistula repair and who underwent urinary diversion and ileal conduit, all had malignancy and complex fistulae. Such major surgery with its implications was only performed after intense discussion and counseling. In these circumstances surgery achieved the desired effect of improved quality of life. Thus urinary diversion has a definite role in the scenario of complex fistula.

\section{Conclusions}

Most non obstetrical vesicovaginal fistulae remain largely iatrogenic. In our setting, timing of surgery had no apparent impact on final outcome. The type of approach depends on the preference and experience of the surgeon, with different approaches offering equally good results at our institution. The principles of fistula repair and case selection remain important determinants of outcome. Urinary diversion is viable for a select minority of patients. Most vesicovaginal fistulae are readily amenable to surgical repair with good outcome.

\section{References}

1. Ekanem EI, Ekott MI, Ekabua JE, et al. Outcome of management of Obstetric genitor-urinary fistulae in the general hospital, Ikot Ekpene, Akwa Ibom state, Nigeria. Urogynaecologia 2010;24:e1.

2. Langkilde NC, Pless TK, Lundbeck F, Nerstrom B. Surgical repair of vesicovaginal fistulae, A ten-year retrospective study. Scand J Urol Nephrol 1999;33:100-4.

3. Tebeu PM, Rochat CH, Kasia JM, Delvaux T. Perception and attitude of obstetric fistula patients about their condition: a report from the Regional Hospital Maroua,
Cameroon. Urogynaecologia 2010;24:e2.

4. Couvelaire R. Reflections on a personal statistics of 136 vesicovaginal fistulas. J Urol Medicale Chir 1953;59:150-60.

5. Woo HH, Rosario DJ, Chapple CR. The treatment of vesicovaginal fistulae. Eur Urol 1996;29:1-9.

6. Stothers L, Chopra A, Raz S. Vesicovaginal fistula. In: Raz S, ed. Female urology. Philadelphia, London; WB Saunders Co; 1996. pp 492-506.

7. Eilber KC, Kavaler E, Rodriguez LV, et al. Ten-year experience with vesicovaginal fistula repair using tissue interposition. $\mathrm{J}$ Urol 1998;160:728-30.

8. Hadley HR. Vesicovaginal fistula. Curr Urol Rep 2002;3:401-7.

9. O'Conor VJ Jr, Sokol JK, Bulkley GJ, Nanninga JB. Suprapubic closure of vesicovaginal fistula. J Urol 1973;109:51-4.

10. Goodwin WE, Scardino PT. Vesicovaginal and ureterovaginal fistulas: a summary of 25 years of experience. J Urol 1980; 123:370-4.

11. Lee RA, Symmonds RE, Williams TJ. Current status of genitourinary fistula. Obstet Gynaecol 1988;72:313-9.

12. Iselin CE, Aslan $\mathrm{P}$, Webster GD. Transvaginal repair of vesicovaginal fistulas after hysterectomy by vaginal cuff excision. J Urol 1998;160:728-30.

13. Sotelo R, Mariano MB, Garcia-Segui A, et al. Laparoscopic repair of vesico vaginal fistula. J Urol 2005;173:1615-8.

14. Wang Y, Hadley HR. Nondelayed transvaginal repair of high lying vesicovaginal fistula. J Urol 1990;144:34-36.

15. Kapoor R, Ansari MS, Singh P, et al. Management of vesicovaginal fistula: An experience of 52 cases with a rationalized algorithm for choosing the transvaginal or transabdominal approach. Indian J Urol 2007;23:372-6. 